\title{
Effect of Salmon-Calcitonin on In Vitro Opioid Withdrawal
}

\author{
M. José Alfaro, Beatriz Fernández, Carlos Goicoechea and M. Isabel Martín* \\ Departamento de Farmacologia, Facultad de Medicina, Universidad Complutense de Madrid, 28040 Madrid, Spain \\ Received March 14, $1997 \quad$ Accepted July 18, 1997
}

\begin{abstract}
The effect on the in vitro withdrawal sign induced by naloxone in morphine-dependent guinea pig ileum has been analyzed. Salmon calcitonin (s-CT) dose-dependently reduced the force of the contraction induced by naloxone in morphine incubated tissues, but did not modify the contraction induced by administration of acetylcholine or substance $P$ in non-treated tissues. Therefore, the effect of s-CT in morphine incubated tissues may not be attributable to postsynaptic mechanisms, and an inhibitory modulation of the excitatory pathways triggered by naloxone would be suggested. In conclusion, s-CT is able to prevent the withdrawal sign in vitro.
\end{abstract}

Keywords: Morphine withdrawal, Opioid abstinence, Calcitonin

Calcitonin (CT) is a polypeptide hormone involved primarily in the regulation of calcium homeostasis that also induces central effects including behavioral changes and analgesia demonstrated in laboratory animals and humans $(1,2)$.

The mechanisms underlying the antinociceptive effect of CT are not known, and opioid and non-opioid mechanisms have been postulated. The non-opioid mechanism is supported by the lack of tolerance to repeated administration (1) and the opioid mechanism is suggested because of the enhancement of endogenous opioid release found after CT administration (3) and because of the modifications induced by salmon calcitonin (s-CT) in vitro on the opioid effects (4).

Considering the involvement of $\mathrm{CT}$ in calcium metabolism regulation and the suggested relationship between CT and the opioid system $(1,4)$, along with the fact that many acute and chronic effects of the opioids can be explained by modifications of the calcium fluxes in neurons (5) and/or by changes in synaptosomal calcium (6), it would be interesting to examine the influence of s-CT on opioid withdrawal.

There is yet only sparse data concerning this subject: the effect of eel CT on the withdrawal syndrome in morphine-dependent rats (7) has been studied; the authors described a decreased incidence of some symptoms such as jumping latency, weight loss or diarrhea after the chronic administration of eel CT. Some effects of intra-

\footnotetext{
* To whom correspondence should be addressed.
}

nasal CT on opioid withdrawal (8) in human opioid addicts have been described, and the results support the possibility that CT may be a useful treatment for opiate withdrawal, without severe side effects. It has been described that $\mathrm{CT}$ is able to increase the release of $\beta$-endorphin (9); however, Vescovi et al. (8) did not find any modification of the $\beta$-endorphin levels in the patients in this study, and therefore this effect was discarded by the authors as the cause of the anti-withdrawal effect, so the mechanism involved remains undetermined.

Our purpose was to study the effect of s-CT on morphine withdrawal. We analyzed the effect of CT on the in vitro withdrawal sign in the myenteric plexus-longitudinal muscle (MP-LM) strips of guinea pig ileum. It is an accepted fact that naloxone can induce a contractile response in MP-LM strips incubated with morphine. This response may be considered as a withdrawal sign (10). There is evidence for the involvement of acetylcholine (ACh) and substance $\mathrm{P}$ (SP) in the mediation of the naloxone contracture (11).

This preparation has been used because dependence is reduced to a single sign and so it is easier to study. Interestingly, drugs useful in reducing opioid withdrawal, such as clonidine or calcium antagonists (12), have been shown to be capable of reducing this contraction.

A portion of $20 \mathrm{~cm}$ of the caudal small intestine was obtained from adult guinea pigs weighing $300-400 \mathrm{~g}$, killed by decapitation. MP-LM preparations were obtained from $5-\mathrm{cm}$ segments of guinea pig ileum as previously described (13) and suspended in an organ bath con- 
taining $10 \mathrm{ml}$ of Krebs solution (118 mM NaCl, $4.75 \mathrm{mM}$ $\mathrm{KCl}, 2.54 \mathrm{mM} \mathrm{CaCl}, \quad 1.19 \mathrm{mM} \quad \mathrm{KH}_{2} \mathrm{PO}_{4}, 1.2 \mathrm{mM}$ $\mathrm{MgSO}_{4}, 25 \mathrm{mM} \mathrm{NaHCO}$ and $11 \mathrm{mM}$ Glucose) at $36^{\circ} \mathrm{C}$ and aerated with $95 \% \mathrm{O}_{2}$ and $5 \% \mathrm{CO}_{2}$. The MP-LM strips were attached to force-displacement transducers, and the contractile activity was recorded on a Grass model 7A polygraph (Grass Instrument, Quincy, MA, USA). A resting tension of $1 \mathrm{~g}$ was applied and maintained on each tissue, and these preparations were allowed to equilibrate for $15 \mathrm{~min}$ before control measurements were carried out.

In order to discard poorly functioning tissues, the responsiveness of each preparation was tested. Electrically induced contractions were evoked using a Grass SD9 stimulator delivering single square wave pulses of $2-\mathrm{msec}$ duration, $0.3-\mathrm{Hz}$ frequency and supramaximal voltage, through two platinum ring electrodes. Tissues with a contractile response smaller than $0.5 \mathrm{~g}$ were rejected. After this test, the stimulation was discontinued and the rest of the experiments were carried out without electrical stimulation. Each MP-LM strip preparation was used only once.

To make the tissues dependent on morphine, a set of them were incubated with $1 \mu \mathrm{M}$ morphine for $2 \mathrm{hr}(12)$.
The dependence was tested by addition of naloxone in a concentration of $0.1 \mu \mathrm{M}$ in the organ bath. The maximum force of the contraction was evaluated as a reliable withdrawal sign $(10-12)$.

The effect of naloxone was tested on the following groups of MP-LM strips: 1 . Control group: maintained in the organ bath for $2 \mathrm{hr}$ without other treatment; 2 . Incubated with s-CT: maintained for $1 \mathrm{hr}$ and $30 \mathrm{~min}$ in the organ bath and then incubated with s-CT $(0.1,0.2,0.4$ or $0.8 \mathrm{IU} / \mathrm{ml}$ ) for $30 \mathrm{~min} ; 3$. Incubated with morphine for 2 $\mathrm{hr} ; 4$. Incubated with morphine and s-CT: the tissues were incubated with morphine for $2 \mathrm{hr}$, with s-CT $(0.1,0.2,0.4$ or $0.8 \mathrm{IU} / \mathrm{ml}$ ) added to the organ bath for the last $30 \mathrm{~min}$ of the incubation period; 5 . Incubated with morphine and clonidine: the tissues were incubated with morphine for 2 hr, with clonidine $(0.1 \mu \mathrm{M})$ added to the organ bath for the last $30 \mathrm{~min}$ of the incubation period.

In a second set of experiments, the effect of s-CT $(0.8$ $\mathrm{IU} / \mathrm{ml}$ ) was tested on the contractions induced by $\mathrm{ACh}$ or by SP. Both drugs were added to the organ bath in a concentration able to induce a contraction of approximately $1 \mathrm{~g}$. The administration of ACh or SP was repeated each $30 \mathrm{~min}$, until a steady response was obtained. Then s-CT was added, and $30 \mathrm{~min}$ later, the ACh or SP

\section{Force of the contraction (g)}

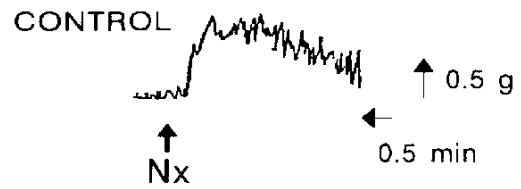

$1.01 \pm 0.13$

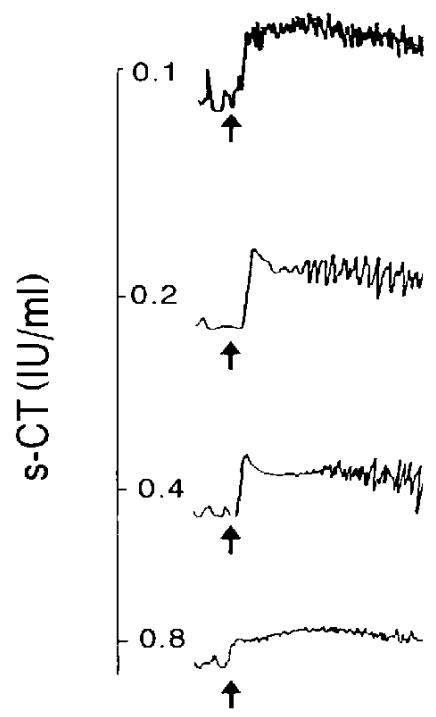

$1 \pm 0.13$

$0.88 \pm 0.21$

$0.78 \pm 0.11$

$0.56 \pm 0.09$

Fig. 1. The traces show the isotonic contraction induced by naloxone (Nx) in morphine-dependent guinea pig ileum, in tissues incubated only with morphine (control) or with morphine and salmon-calcitonin (s-CT). The column in the right shows the mean \pm S.E.M. of the force of the contraction induced by naloxone $(n=6)$. 


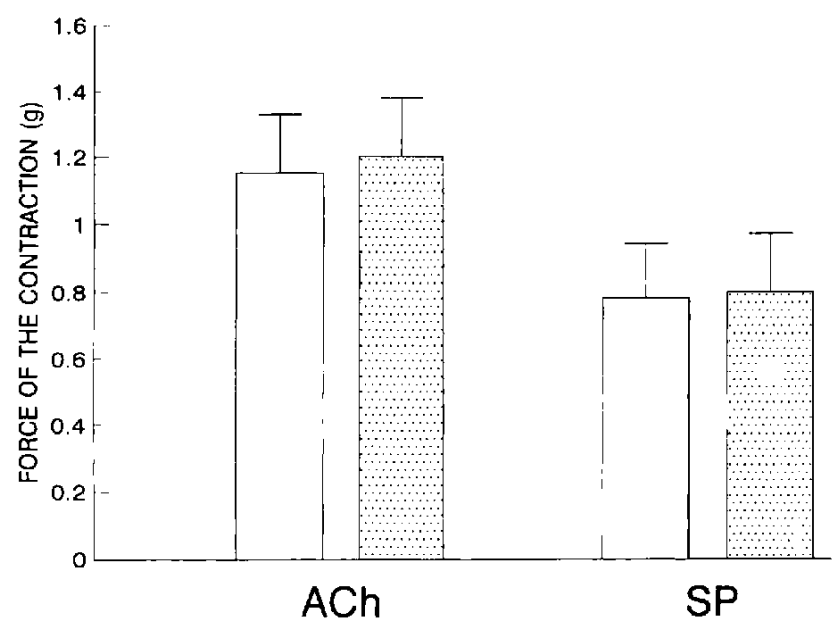

Fig. 2. Bars show the mean \pm S.E.M. of the force of the contraction induced by acetylcholine $(\mathrm{ACh})$ or substance $\mathrm{P}(\mathrm{SP})$ in the control (open bars) and salmon-calcitonin $(0.8 \mathrm{IU} / \mathrm{ml})$ (dotted bars) incubated tissues $(n=6)$.

was again added to the organ bath. The induced contraction was compared with the control (the force of the last contraction before s-CT addition).

Data analyses: The results are expressed as the mean of at least 6 experiments \pm S.E.M. Statistical analyses was performed by analysis of variance (ANOVA), follwed by the LSD post-hoc test. Differences were accepted as significant when $\mathrm{P}<0.05$.

Acetylcholine $\mathrm{HCl}$ (Sigma, Madrid, Spain), clonidine (kindly supplied by Boehringer Ingelheim S.A., Madrid, Spain), morphine $\mathrm{HCl}$ (Alkaliber Laboratories, Madrid, Spain), naloxone (Sigma), salmon calcitonin (kindly supplied by Rhône Poulenc-Rorer, Madrid, Spain) and substance $P$ (Sigma).

In the MP-LM strips, the addition of naloxone to the organ bath did not induce any contractile response in the control or s-CT-treated tissues. In tissues incubated with morphine, naloxone elicited a contraction, this response being accepted as a sign of morphine-dependence. As expected, the incubation with clonidine decreased the force of the contraction induced by naloxone; the mean \pm S.E.M. of the force $(\mathrm{g})$ of the contraction was $0.9 \pm 0.02$ in morphine-treated tissues and $0.6 \pm 0.12$ in morphine plus clonidine $(0.1 \mu \mathrm{M})$-treated tissues, the difference being statistically significant $(P<0.01)$.

When morphine-dependent tissues were incubated with $\mathrm{s}-\mathrm{CT}$, the contractile response elicited by naloxone was inhibited in a dose-dependent manner (Fig. 1).

The addition to the organ bath of ACh $(0.5-1 \mu \mathrm{M})$ or SP $(0.1-0.5 \mu \mathrm{M})$ induced a contraction of almost $1 \mathrm{~g}$. The incubation during $30 \mathrm{~min}$ with $\mathrm{s}-\mathrm{CT}(0.8 \mathrm{IU} / \mathrm{ml}) \mathrm{did}$ not modify the force of these contractions (Fig. 2).

In an attempt to approach the mechanism involved in the effect of s-CT on opioid withdrawal, we have used an in vitro model that is widely used and which yields results that can be analyzed more easily than data obtained in in vivo assays. It is accepted that the contracture induced by naloxone in morphine-incubated guinea pig ileum is an expression of opioid dependence $(10-12)$. This contracture seems to be mediated not only by the release of $\mathrm{ACh}$, the major transmitter of the myenteric neurons acting on longitudinal muscle (14), but also by SP (11).

Our results show that $\mathrm{CT}$ is able to reduce in a dosedependent manner the contraction elicited by naloxone in morphine-dependent tissues, this effect being similar to that obtained when the tissues were treated with clonidine. It is well-known that this $\alpha_{2}$-adrenergic agonist reduces the opioid withdrawal in animals and humans as well as the naloxone-induced contraction (12); thus it has been used as a control to measure the effectivity of the s-CT.

On the other hand, s-CT was incapable of modifying the contracture induced by administration of ACh or SP, even at the highest tested dose. These data suggest that its effect on the naloxone-induced contraction cannot be mediated through postsynaptic mechanisms involved in the smooth muscle contractility or through interactions with postsynaptic receptors for ACh or SP.

From this result, it may be concluded that $\mathrm{s}-\mathrm{CT}$ acts in this tissue as an inhibitory modulator of the excitatory pathways that naloxone triggers in morphine-dependent tissues.

Considering that CT increases the in vitro effect of opioid agonists (4), this may be one of the reasons why it decreases the withdrawal sign induced by naloxone. In the present study, to induce opioid dependence, we incubated the MP-LM strips with morphine, a preferential $\mu$ agonist. It has been previously demonstrated (15) that the withdrawal contracture can be achieved by very low concentrations of a $\kappa$-antagonist in preparations rendered dependent on a $\mu$-agonist such as morphine. These data suggest that the dependence induced by a $\mu$-agonist involves $\mu$ - and $\kappa$-receptors. So the CT-induced reduction of the withdrawal sign may be mediated through an increase in the morphine activity on $\mu$ - or $\kappa$-opioid receptors.

Although these data, in agreement with previous reports $(7,8)$, indicate that $C T$ may partially attenuate the symptomatology of opioid withdrawal, in our opinion, more experimental work is required before $\mathrm{CT}$ might be considered a useful supportive measure for opioid withdrawal.

\section{Acknowledgments}

This work was supported by Laboratories del Dr. ESTEVE S.A., Spain. 


\section{REFERENCES}

1 Braga P, Ferri S, Santangostino A, Ogliati V and Pecile A: Lack of opiate receptor involvement in centrally induced calcitonin analgesia. Life Sci 22, 971 - 977 (1978)

2 Welzel M, Schultz $\mathbf{R}$ and Herz A: Calcitonin relieves pain in patients suffering from bone cancer. In Calcitonin 1984: Proc Int Symp, Excerpta Medica, Amsterdam (1985)

3 Collin E, Bourgoin S, Gorce P, Hamon M and Cesselin F: Intrathecal porcine calcitonin enhances the release of [met]enkephalin-like material from the rat spinal cord. Eur J Pharmacol 168, $201-208$ (1989)

4 Martín MI, Alfaro MJ, Goicoechea C and Colado MI: In vitro study of the interaction of salmon calcitonin with $\mu, \delta$ and $\kappa$ opioid agonists. Naunyn Schmiedebergs Arch Pharmacol 347, 324-328 (1993)

5 Guerrero-Muñoz F, Cerreta KW, Guerrero ML and Way EL: Effect of morphine on synaptosomal $\mathrm{Ca}^{2+}$ uptake. J Pharmacol Exp Ther 209, 132 - 136 (1979)

6 Xiang JZ, Brammer MJ and Campbell IC: Studies of receptormediated inhibition of ${ }^{45} \mathrm{Ca}$ accumulation into synaptosomes. Br J Pharmacol 101, 140-144 (1990)

7 Clementi G, Valerio C, Prato A, Carusio A, Patti F, Patane S and Drago F: Effects of calcitonin on morphine tolerance and withdrawal syndrome in morphine physically dependent rats. Eur J Pharmacol 163, 175-179 (1989)
8 Vescovi PP, Michelini M, Maninetti L, Pedrazzoni M, Pioli G, Zaniboni $G$ and Passeri $M$; Calcitonin nasal spray reduces opioid withdrawal syndrome without modification of endogenous opioid secretion. Recenti Prog Med 83, 23-26 (1992)

9 Laurian L, Oberman Z, Graf E, Gilod S, Hoerer E and Simantov $\mathrm{R}$ : Calcitonin induced increase in $\mathrm{ACTH}, \beta$-endorphine and cortisol secretion. Horm Metabol Res 18, 268-271 (1986)

10 Rezvani A, Huidobro-Toro JP, Hu J and Way L: A rapid and simple method for the quantitative determination of tolerance development to opiates in the guinea-pig ileum in vitro. $J$ Pharmacol Exp Ther 225, 251-255 (1993)

11 Gintzler AR: Substance P involvement in the expression of gut dependence on opiates. Brain Res 182, 224-228 (1980)

12 Alfaro MJ, Colaro MI, López F and Martín MI: Effect of clonidine, nimodipine and diltiazem on the in vitro opioid withdrawal response in the guinea-pig ileum. $\mathrm{Br} \mathrm{J}$ Pharmacol 101, 958-960 (1990)

13 Ambache N: Separation of the longitudinal muscle of the rabbit's ileum as a broad sheet. J Physiol (Lond) 125, 53-54 (1954)

14 Paton WDM: The action of morphine and related substances on contraction and on acetylcholine output of coaxially stimulated guinea-pig ileum. Br J Pharmacol Chemother 12, $119-127$ (1957)

15 Schulz R, Seidl E and Herz A: Opioid dependence in the guineapig myenteric plexus is controlled by non-tolerant and tolerant opioid receptors. Eur J Pharmacol 110, 335-341 (1985) 